\title{
Finding food in a human-dominated environment: Exploring the foraging behaviour of urban Torresian Crows Corvus orru
}

\author{
Briana Clifton and Darryl N. Jones* \\ Suburban Wildlife Research Group, Environmental Futures Research Institute, \\ Griffith University, Nathan QLD 4111, Australia \\ *Corresponding author. Email: D.Jones@griffith.edu.au
}

\begin{abstract}
Urbanisation provides both challenges and opportunities for wildlife living within these novel environments. Corvids (crows and ravens), although naturally wary and neophobic, have become among the most abundant urban bird groups throughout the world. Although such success has been attributed to their exploitation of human-derived food wastes, the foraging behaviour of urban corvids is poorly understood. We investigated foraging among Torresian Crows Corvus orru in suburban Brisbane, Queensland, by observing their behaviour at 15 parks and commercial sites in 2014-2015. The items consumed by foraging crows were identified specifically and with regard to origin during 5-minute focal observations. In addition, the reactions of birds to the presence of humans were noted. We found that the diet of the species was dominated by natural foods, especially insects, although around a third of items were of human origin. Crows selected a very wide range of food types and were more likely to consume natural foods during the morning but anthropogenic foods during the middle of the day. Crows were prone to flying away from a foraging site if people were close by. This study demonstrated that urban Torresian Crows rely primarily on natural foods, probably switching to scavenging only when nutritional needs have been met.
\end{abstract}

\section{Introduction}

Urbanisation is a rapid modifier of the environment with many profound impacts on biodiversity (Moller et al. 2014). Currently, just over half of the total global human population lives in urban areas and this is projected to increase to $66 \%$ by 2050 (United Nations 2014). This process will result in significant environmental changes as natural and rural environments are rapidly transformed into urbanised landscapes (Meffert \& Dziock 2013). Species living within these transformed environments have to contend with multiple challenges including habitat fragmentation, alteration of traditional food sources, increases in human disturbance and changes in avian community composition (Sol et al. 2013). Although many species are unable to adapt to the altered conditions (Jones 2003), others successfully exploit these anthropogenic environments, taking advantage of the opportunities presented (Blair 1996; Marzluff \& Neatherlin 2006; Sol et al. 2013).

One of the greatest of these opportunities is the increased availability of a wide range of anthropogenic foraging resources, although exploiting these requires the ability to adapt to both the different forms of food and to the presence of humans. Despite being naturally cautious and wary of new objects (Brown \& Jones 2016), corvids (family Corvidae: crows, ravens and jays) have become proficient exploiters of the urban environment throughout the world (Marzluff et al. 2001). In many cases, urban corvid populations have increased dramatically, a phenomenon often attributed to their exploitation of anthropogenic foods (Everding 1995; Marzluff \& Neatherlin 2006; Webb et al. 2011; but see Lill \& Hales 2015). The success of corvids as urban exploiters (Blair 1996) has been characterised by numerous behavioural traits including regular, long and unidirectional travel to foraging sources (Marzluff \& Neatherlin 2006), preferential nesting and roosting near predictable and persistent food resources (Everding \& Jones 2006; Webb et al. 2011) and major changes in feeding ecology including the consumption of novel types of foods, often from substrates very different from those used traditionally (Kristan et al. 2004).

However, species cannot successfully inhabit a city without first overcoming their natural aversion towards people (a form of habituation), a necessary step for coexistence in urban environments (Luniak 2004). Direct forms of human persecution such as shooting and nest destruction have had major impacts on the behaviour of many species, with corvids in particular being targeted throughout the world (Knight et al. 1987). Although such actions tend to be more intense in rural areas, some corvids are also subject to intolerance and aggressive interactions in urban environments (Marzluff \& Neatherlin 2006). All forms of persecution delay or hinder habituation, potentially impeding the ability of corvids to successfully exploit the available foraging resources of urban environments (Vuorisalo et al. 2003).

Currently, little is known about the way in which anthropogenic food subsidies and human disturbance have influenced the behaviour of urban corvids. Despite the abundance of crows and their allies in cities around the world, remarkably few studies have been undertaken on urban corvid foraging behaviour; this is surprising given the central role that anthropogenic foods have apparently played in their success (Marzluff et al. 2001). Among Australian corvid species, important studies have been conducted on Australian Ravens Corvus coronoides in Perth, Western Australia (Moon 2005), and Little Ravens C. mellori in Melbourne, Victoria (Lill \& Hales 2015; Vines \& Lill 2015), which have included information on foraging behaviour. In tropical Australia, the Torresian Crow C. orru is the predominant corvid, and has colonised most towns in the region including the largest city, Brisbane, 
Queensland (Sinden 2002). Although numerous aspects of the behaviour of this species have been investigated in Brisbane (Sinden 2002; Everding \& Jones 2006; Brown \& Jones 2016), foraging ecology has been neglected. The aims of the present study were to investigate the foraging ecology of the Torresian Crow in the suburbs of Brisbane by determining its diet, whether foraging activities changed throughout the day, and how proximity to people influenced its behaviour.

\section{Methods}

Data collection was undertaken between May 2014 and February 2015 within 15 sites located throughout the southeastern suburbs of Brisbane. All sites were recreational parks, gardens and commercial areas accessible to the public and were separated by at least $2 \mathrm{~km}$. Criteria for the selection of sites included the presence of the study species, regular benign human presence (no active sports activities) and relatively unrestricted viewing. The latter condition precluded typical house yards. Although not quantified, the level of anthropogenic foods was relatively similar in all sites. Each site was visited for three consecutive days where possible, with data recorded during three discrete observation sessions per day: morning (sunrise-0900 h), midday (1130-1300 h) and afternoons (1530 h-sunset) though with different sites visited only once per day. The relative age of all individual crows included in samples was determined by eye colour (Rowley 1970); reliably distinguishing sex by observation is not possible. Juveniles were not included in analyses.

Data collection had three separate foci: food type, distance from people and foraging activity.

\section{Food origin and type}

Observations of the types of food being consumed or taken by crows were made during 5-minute focal sampling units (Martin \& Bateson 2007) where an individual crow was randomly selected (typically the nearest individual to the observer) from within a group detected moving on the ground (and therefore potentially foraging). To avoid the possibility of sampling the same individuals, different parts of sites were visited during each subsequent session. Although this approach and the random selection of focal birds reduced the probability of re-sampling, we cannot be certain that this did not occur in some cases. Nonetheless, because of the relatively large number of individuals sampled and the short observation time, we believe that the necessary assumption of statistical independence was met. Food that was 'taken' refers to an item being collected by a focal bird but removed from the site; it was assumed that these items were later consumed or cached. The type of food consumed or taken was recorded, both as one of four main origin categories (anthropogenic, natural, roadkill and unknown), and as specifically as possible. At least five focal samples containing a complete record were taken per session (morning, midday and afternoon) at each site, across the 3 days.

Binoculars or a camera-borne telephoto lens were used to minimise disturbance and assist in sampling at distances $>30 \mathrm{~m}$. The camera-borne telephoto lens was employed when obtaining direct observations was difficult (such as when multiple crows obscured the focal bird), with the subsequent recording being reviewed later.

Differences between food types consumed and time of day, combined for all days, was assessed using a chisquare test. Because one of the food types, road-kill, yielded less than five items, this category was omitted from the test. Therefore, the chi-square test was conducted on three food types (anthropogenic, natural and unknown) across the three time periods (morning, midday, afternoon).

\section{Distance from people}

The distance between the focal individual and the nearest person was estimated visually for each foraging event recorded. Differences between the mean distance of people from the food and whether the individual crow moved or consumed the food item on the spot were analysed using an independent $t$-test. Samples in which no people were in sight (recorded as a distance of zero) were omitted from this test.

\section{General activity}

In order to obtain information relating to the general activities of groups of foraging crows as a whole, scan samples (Martin \& Bateson 2007) were carried out during the three sessions over three consecutive days, where possible, at the 15 sites. Scan samples lasted for 5 minutes, with the entire group being scanned every 30 seconds. During each scan, the behavioural states of individuals were instantaneously classified into one of five general activity categories (fly, walk, perch, forage or preen). As these samples were designed to record the activities at the group level, a minimum of three individuals was required to commence a scan. In the event of birds moving out of sight during the scan, the presence of more than one individual was required to complete the sample. A comparison of behavioural states between the three times of day was performed with a chi-square test using proportions combined for all sessions.

\section{Results}

During the study, a total of 287 individual Torresian Crows was observed over c. 170 hours of observations. The sampled individuals consisted of $13(4.5 \%)$ juveniles of 3 to 11 months, $191(66.5 \%)$ adults older than 1 year and 10 months, and 83 (29.0\%) individuals of unknown age.

\section{Food origin and type}

There was a distinct difference in the general type of food consumed and the time of day $\left(X^{2}=44.039\right.$, $\mathrm{df}=4$, $P<0.0001)$. Although the proportion of items that could not be reliably identified was fairly consistent during the three periods, there was a distinct pattern of natural items being consumed more frequently during mornings and anthropogenic items dominating during the midday period (Figure 1). The proportion of the diet made up of anthropogenic items increased from $20 \%$ in the mornings to $>50 \%$ during the middle of the day. The proportions of natural and anthropogenic items in the diet during the afternoon were fairly similar.

Wherever possible, the food items consumed or taken were identified as precisely as practicable. These items 


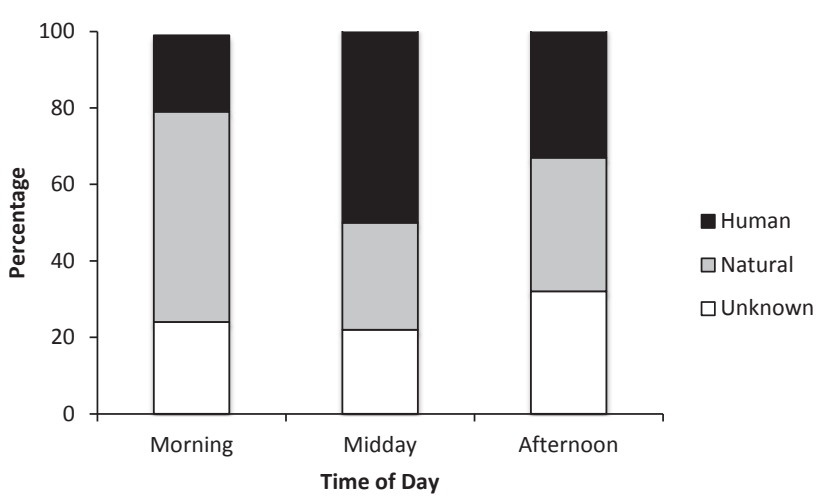

Figure 1. Percentage of food by origin consumed by Torresian Crows at different times of the day.

were then classified into general food types. Table 1 lists these food types in order of the proportion they comprised of the entire diet in all observations during all sessions combined. This table also includes the origin of the items but does not include the items categorised as 'unknown'.

Considered as a whole, the diet of suburban Torresian Crows consisted of $63 \%$ natural items and $37 \%$ anthropogenic. By far the most predominant food type consumed was 'insects' (including some spiders) which made up almost all of the largest category identified, invertebrates. Nonetheless, the second most common food category comprised various discarded breads and pastries, and a relatively large amount of litter was taken, presumably because some form of food was attached or contained within.

\section{Distance from people}

Torresian Crows were significantly more likely to leave the foraging site with a food item if people were nearby

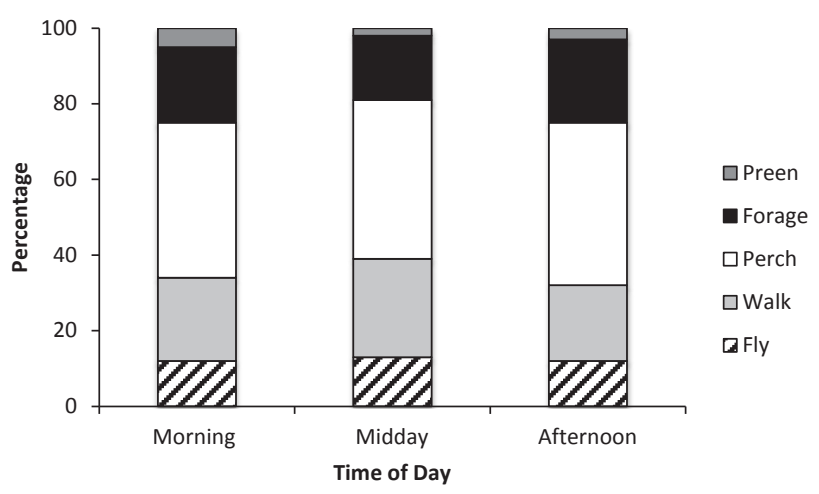

Figure 2. Percentage of general actions of Torresian Crows at different times of the day.

(Satterthwaite approximate $t$-test: $t=13.6, \mathrm{df}=69$, $P<0.0001)$. The mean distance from people at which foraging crows left the area was $5.4 \pm$ standard deviation $1.62 \mathrm{~m}$ (range 1-10 m). In contrast, crows were willing to consume the item in situ if people were on average 12.3 $\pm 2.6 \mathrm{~m}$ (range $2.5-25 \mathrm{~m}$ ) away.

\section{Activity}

Overall, the proportion of time spent performing the five main forms of activity undertaken by groups of crows engaged mainly in foraging was found to be significantly different during different times of the day (Chi-square test: $\left.X^{2}=89.7169, \mathrm{df}=8, P<0.0001\right)$. The frequencies of walking and preening were higher than expected during the morning, whereas perching was less frequent than expected (assuming equal representation). Of particular relevance to this study, the frequency of foraging was less than expected during the midday period and higher than expected during the afternoon (Figure 2).

Table 1. Types and origins of food items consumed or taken by Torresian Crows in suburban Brisbane, Queensland. The third column displays the percentage of each food type in the total of all known food items (unknown items were excluded from this total).

\begin{tabular}{llc}
\hline \multicolumn{1}{c}{ Food type (and origin) } & \multicolumn{1}{c}{ Description } & Percentage \\
\hline $\begin{array}{l}\text { Invertebrates } \\
\text { (Natural) }\end{array}$ & $\begin{array}{l}\text { Included annelids, flying insects, spiders, spider } \\
\text { eggs, beetles, moths, ants and unidentifiable } \\
\text { insects. (Insects made up 99.6\% of all } \\
\text { inverterbrate items.) }\end{array}$ & 46.4 \\
\hline $\begin{array}{l}\text { Bread, pastry and barbeque scraps } \\
\text { (Anthropogenic) }\end{array}$ & $\begin{array}{l}\text { Included bread, chips, biscuit crumbs, pizza } \\
\text { crusts, and food scraps baked onto a barbeque. }\end{array}$ & 25.4 \\
\hline $\begin{array}{l}\text { Unknown natural food } \\
\text { (Natural) }\end{array}$ & $\begin{array}{l}\text { Items appeared to be natural in origin but could } \\
\text { not be identified. }\end{array}$ & 13.3 \\
\hline $\begin{array}{l}\text { Food associated with litter } \\
\text { (Anthropogenic) }\end{array}$ & $\begin{array}{l}\text { Included food attached to packaging, take-away } \\
\text { bags, wrappers, serviettes and packets; sources } \\
\text { were as either discards or from waste bins. }\end{array}$ & 6.2 \\
\hline $\begin{array}{l}\text { Unknown anthropogenic food } \\
\text { (Anthropogenic) }\end{array}$ & $\begin{array}{l}\text { Foods appeared to be anthropogenic in origin } \\
\text { but could not be identified. }\end{array}$ & 3.4 \\
\hline $\begin{array}{l}\text { Seeds and berries } \\
\text { (Natural) }\end{array}$ & \begin{tabular}{l} 
Items naturally available on vegetation. \\
\hline $\begin{array}{l}\text { Fruit } \\
\text { (Anthropogenic) }\end{array}$
\end{tabular} & $\begin{array}{l}\text { Items available through discarding, including } \\
\text { watermelon rind, grape, avocado, apple core }\end{array}$ \\
\hline $\begin{array}{l}\text { Carrion (dead possum) } \\
\text { (Natural) }\end{array}$ & and tomato. \\
\hline
\end{tabular}




\section{Discussion}

Corvids have become among the most abundant avian taxa found in urban environments throughout the world (Marzluff et al. 2001). This abundance is despite millennia of active persecution and antipathy in both rural and urban areas (Knight 1984) and, unlike many other urban exploiters (Blair 1996), innate behavioural characteristics that include neophobia and a persistent lack of habituation (Brown \& Jones 2016). Nonetheless, urbanised corvids can demonstrate clear evidence of tolerance of human presence; Vines \& Lill (2015) showed that Little Ravens in urban Melbourne allowed humans to approach far closer than conspecifics in exurban areas. A major component of this perhaps unexpected success of urban corvids has been attributed to their utilisation of readily available anthropogenic foods (Sinden 2002). In other words, crows appear to be successful in cities primarily because they scavenge human waste products (Jones 2003). Our study has revealed that this generalisation is far from accurate. Here we demonstrate that the diet of urban Torresian Crows in Brisbane was dominated by various natural food types, with by far the largest proportion being made up of arthropods, and that, although foraging Torresian Crows did avoid the presence of people, this did not prevent them from foraging. Similarly, Lill \& Hayes (2015) reported that the diet of Little Crows in Melbourne was dominated by a wide variety of natural food items despite an abundance of discarded human foods.

There were also several important changes in the foraging ecology of these birds with time of day. Natural foods were consumed more during the morning, whereas anthropogenic foods were sought more during the midday period; about equal proportions of these two food types were consumed during afternoons. A similar result was also obtained by Sinden (2002), who found that Torresian Crows in Brisbane consumed considerably more natural than anthropogenic food during the morning. The consumption of predominantly natural foods early in the day has been reported in a wide variety of urban bird species, including other species similarly regarded as scavengers of human waste. For example, Australian White Ibis Theskiornis moluccus, Australian Magpies Gymnorhina tibicen and Common Starlings Sturnus vulgaris obtain most of their estimated nutritional requirements by feeding on invertebrates during the early morning, with their more conspicuous scavenging coming later in the day (Mennechez \& Clergeau 2001; O'Leary \& Jones 2006; Meyer-Gleaves \& Jones 2007). Importantly, these studies showed that the exploitation of anthropogenic foods occurred during the middle of the day, presumably after the birds' nutritional needs had been met (O'Leary \& Jones 2006).

The change from predominantly natural to anthropogenic foods with time of day appeared to be associated with an increase in human activity during the middle of the day and the discarding of anthropogenic food sources. These activities in parklands and greenspace in cities create a predictable and reliable foraging location for crows and other species (Oro et al. 2013; Boggie \& Mannan 2014). In the afternoon, when some human activity decreases, Torresian Crows obtained similar amounts of natural and human foods.
The remarkable range of foods consumed by urban Torresian Crows demonstrates clearly a highly versatile diet and a willingness to try thoroughly unfamiliar items. Although Brown \& Jones (2016) recently found this species to be strongly neophobic, being reluctant to approach a familiar food item when a novel object was nearby, it appears that this characteristic is overcome with time. For example, the various forms of packaging (foil, paper bags, packets etc.) would all have been entirely novel when first encountered, yet these were commonly exploited by the birds in the present study. This ability of Torresian Crows to identify and exploit a wide variety of edible anthropogenic items would have been highly advantageous in their colonisation of the urban environment (Sinden 2002).

Habituation is the reduction of sensitivity and response from repeated exposure to stimuli, with boldness towards humans considered an outcome of this process (Evans et al. 2010). Corvids are known to habituate gradually to nonthreatening situations (Blumstein 2006). Torresian Crows have been present in Brisbane since the 1950s, with overt persecution within the suburban environment much lower than in rural areas (Everding 1995; Sinden 2002). Similarly, in Europe, Vuorisalo et al. (2003) found that urban Hooded Crows Corvus cornix eventually habituated to the presence of humans once persecution decreased.

Corvids are, nonetheless, flighty and wary birds, able to adjust their reaction based on the general human activities in the area (Clucas \& Marzluff 2012). These attributes would have influenced a crow's decision to depart with food, particularly if startled or threatened. Corvids are highly intelligent and capable of learning rapidly from a brief, single experience, particularly when negative (Marzluff et al. 2010). It is possible that some individuals may have had a negative experience associated with humans and are now wary when in close contact. Frid \& Dill (2002) have explained that anti-predator behaviour is still most likely to occur despite habitation to disturbance, as individuals will often overestimate rather than underestimate the threat of non-lethal stimuli, particularly when they have received imperfect information.

In conclusion, we found Torresian Crows in Brisbane to be careful and attentive when foraging, yet willing to exploit a wide range of traditionally unfamiliar food types. They were proficient and opportunistic exploiters of both natural and anthropogenic foods. Although they obviously do obtain a large amount of their daily diet from scavenging discarded human food wastes, anthropogenic items made up a clear minority of their overall intake. As with other urban bird species, it appears that Torresian Crows obtain the bulk of their nutritional requirements during intensive foraging on natural sources in the early morning, switching to foods of human origin when the intake of foods is less important.

\section{Acknowledgements}

We are grateful to Janet Chaseling for her advice regarding statistical analysis and all others who provided encouragement and support over the period of study.

\section{References}

Blair, R.B. (1996). Land use and avian species diversity along an urban gradient. Ecological Applications 6, 506-519. 
Blumstein, D.T. (2006). Developing an evolutionary ecology of fear: How life history and natural history traits affect disturbance tolerance in birds. Animal Behaviour 71, 389-399.

Boggie, M.A. \& Mannan, R.W. (2014). Examining seasonal patterns of space use to gauge how an accipiter responds to urbanization. Landscape and Urban Planning 124, 34-42.

Brown, M.J. \& Jones, D.N. (2016). Cautious crows: Neophobia in Torresian Crows (Corvus orru) compared with three other corvoids in suburban Australia. Ethology 122, 726-733.

Clucas, B. \& Marzluff, J.M. (2012). Attitudes and actions toward birds in urban areas: Human cultural differences influence bird behavior. Auk 129, 8-16.

Evans, J., Boudreau, K. \& Hyman, J. (2010). Behavioural syndromes in urban and rural populations of Song Sparrows. Ethology 116, 588-595.

Everding, S.E. (1995). Movements of and Habitat Use of the Torresian Crow in a Suburban Environment. MSc thesis. Griffith University, Brisbane.

Everding, S.E. \& Jones, D.N. (2006). Communal roosting in a suburban population of Torresian Crows (Corvus orru). Landscape and Urban Planning 74, 21-33.

Frid, A. \& Dill, L.M. (2002). Human-caused disturbance stimuli as a form of predation risk. Conservation Ecology 6, 11.

Jones, D.N. (2003). Contemporary urban ecology: The view from the Antipodes. In: Tiezzi, E., Brebbia, C.A. \& Usó, J.L. (Eds). Ecosystems and Sustainable Development IV, pp. 745-753. Wessex Institute of Technology Press, Southampton, UK.

Knight, R.L. (1984). Responses of nesting ravens to people in areas of different human densities. Condor 86, 345-346.

Knight, R.L., Grout, D.J. \& Temple, S.A. (1987). Nest-defense behavior of the American Crow in urban and rural areas. Condor 89, 175-177.

Kristan, W.B., Boarman, W.I. \& Crayon, J.J. (2004). Diet composition of common ravens across the urban-wildland interface of the West Mojave Desert. Wildlife Society Bulletin 32, 244-253.

Lill, A. \& Hales, E. (2015). Behavioural and ecological keys to urban colonization by Little Ravens (Corvus mellori). Open Ornithology Journal 8, 22-31.

Luniak, M. (2004). Synurbization-adaptation of animal wildlife to urban development. In: Shaw, W.W., Harris, L.K. \& van Druff, L. (Eds). Proceedings 4th International Urban Wildlife Symposium, pp. 50-55. University of Arizona, Tucson, USA.

Martin, P. \& Bateson, P. (2007). Measuring Behaviour: An Introductory Guide. 3rd edn. Cambridge University Press, Cambridge, UK.

Marzluff, J.M. \& Neatherlin, E. (2006). Corvid response to human settlements and campgrounds: Causes, consequences, and challenges for conservation. Biological Conservation 130, 301-314

Marzluff, J.M., McGowan, K.J., Donnelly, R. \& Knight, R.L. (2001). Causes and consequences of expanding American Crow populations. In: Marzluff, J.M., Bowman, R. \& Donnelly, R. (Eds). Avian Ecology and Conservation in an Urbanizing World, pp. 331-364. Kluwer Academic Publishers, Norwell, Washingtom, USA.

Marzluff, J.M., Walls, J., Cornell, H.N., Withey, J.C. \& Craig, D.P. (2010). Lasting recognition of threatening people by wild American crows. Animal Behaviour 79, 699-707.
Meffert, P.J. \& Dziock, F. (2013). The influence of urbanisation on diversity and trait composition of birds. Landscape Ecology 28, 943-957.

Mennechez, G. \& Clergeau, P. (2001). Settlement of breeding European starlings in urban areas: Importance of lawns vs. anthropogenic wastes. In: Marzluff, J.M., Bowman, R. \& Donnelly, R. (Eds). Avian Ecology and Conservation in an Urbanizing World, pp. 275-288. Kluwer Academic Publishers, Norwell, Washington, USA.

Meyer-Gleaves, S.R. \& Jones, D.N. (2007). Relative abundance of Australian White lbis Threskiornis molluca across the greater Brisbane region. In: Lunney, D., Eby, P., Hutchings, P. \& Burgin, S. (Eds). Pest or Guest: The Zoology of Overabundance, pp. 142-149. Royal Zoological Society of New South Wales, Sydney.

Moller, A.P., Jokimaki, J., Skorka, P. \& Tryjanowski, P. (2014). Loss of migration and urbanization in birds: A case study of the blackbird (Turdus merula). Oecologia 175, 1019-1027.

Moon, D.L. (2005). A Study of the Abundance, Distribution and Daily Activities of the Australian Raven (Corvus coronoides) in Urban Wetland Parks. BA (Hons) thesis. Edith Cowan University, Perth.

O'Leary, R. \& Jones, D.N. (2006). The use of supplementary foods by Australian magpies Gymnorhina tibicen: Implications for wildlife feeding in suburban environments. Austral Ecology 31, 208-216.

Oro, D., Genovart, M., Tavecchia, G., Fowler, M.S. \& Martínez Abraín, A. (2013). Ecological and evolutionary implications of food subsidies from humans. Ecology Letters 16, 1501-1514.

Rowley, I. (1970). The genus Corvus (Aves: Corvidae) in Australia. CSIRO Wildlife Research 15, 27-71.

Sinden, K.E. (2002). Synanthropy of Torresian Crows Corvus orru in the Greater Brisbane Region: Abundance, Foraging and Conflicts. BSc (Hons) thesis. Griffith University, Brisbane.

Sol, D., Lapiedra, O. \& González-Lagos, C. (2013). Behavioural adjustments for a life in the city. Animal Behaviour 85, $1101-1112$.

United Nations (2014). World Urbanization Prospects: The 2014 Revision, Highlights. United Nations Department of Economic \& Social Affairs, Population Division, New York.

Vines, A. \& Lill, A. (2015). Boldness and urban dwelling in little ravens. Wildlife Research 42, 590-597.

Vuorisalo, T., Andersson, H., Hugg, T., Lahtinen, R., Laaksonen, H. \& Lehikoinen, E. (2003). Urban development from an avian perspective: Causes of hooded crow (Corvus corone cornix) urbanisation in two Finnish cities. Landscape and Urban Planning 62, 69-87.

Webb, W.C., Marzluff, J.M. \& Hepinstall-Cymerman, J. (2011). Linking resource use with demography in a synanthropic population of common ravens. Biological Conservation 144, 2264-2273.

Received 27 September 2016, accepted 28 October 2016 , published online 30 March 2017 